\title{
Carrying Stories From the Outside In: A Collaborative Narrative Into a Teacher Education Community
}

\author{
Shelley M. Griffin, Darlene Ciuffetelli Parker, and Julian Kitchen
}

\author{
Brock University
}

\section{Author Note}

This article is based on two previous refereed conference presentations:

Griffin, S., \& Kitchen J. (2009, May). Cradling stories into a self-study circle of teacher education. Paper presented at the Canadian Society for the Study of Education Annual Conference, Capital Connections: Nation, Terroir, Territoire. Carleton University, Ottawa, ON, Canada.

Griffin, S. M., Ciuffetelli Parker, D., \& Kitchen, J. (2008, May). Coming to a new circle: Carrying stories into a self-study context of teacher education. Paper presented at Narrative Matters 2008 "Storying Our World": An Interdisciplinary Conference on Narrative Research, Perspectives, Practices and Issues. University of Toronto, ON, Canada.

Correspondence concerning this article should be addressed to Shelley M. Griffin, Department of Teacher Education, Faculty of Education, Brock University, 500 Glenridge Avenue, St. Catharines, Ontario, Canada, L2S 3A1. Email: sgriffin@brocku.ca

\begin{abstract}
As three professors working collaboratively in teacher education, we reflect on our participation as former graduate students in narrative research circles facilitated by Dr. Jean Clandinin (University of Alberta) and Dr. Michael Connelly (Ontario Institute for Studies in Education, University of Toronto). By drawing upon the stories that we carry from institutions outside Brock University, we inquire into how our narrative experiences inform our current positioning within a teacher education community. Situating our work within social constructionism and narrative inquiry honours our relational, co-constructed work. Reflecting on three central questions regarding our individual research circle experiences assists in understanding how our narratives overlap with our current community. We draw attention to unspoken tensions that are embedded while working in relation. We invite other scholars to consider how collaborative research circle experiences can be a powerful form of living in community and a means of enhancing scholarly writing and practice.
\end{abstract}

Keywords: research circle; research writing; teacher education; narrative inquiry; social constructionism; self-study 


\section{Carrying Stories From the Outside In: A Collaborative Narrative Into a Teacher Education Community}

As three teacher educators within the Faculty of Education at Brock University, we consider the influences that our previous experiences in narrative research circles, within other postsecondary contexts, had in shaping how we live out our new writing and research experiences in our current university setting. Over the past 4 years, we have been members of a self-study group of teacher educators in the Department of Teacher Education. The self-study group, with a strong focus on narrative scholarship, has been a safe space in which we are able to share experiences and collaborate on research. In this context, we have been able to compose stories that allow us to explore who we are and who we are becoming as teacher educators in the shifting social context of our faculty and the wider field of education. Thinking narratively, we recognize that our embrace of this new circle is a response to the rich experiences we had during our years as graduate students in the field of narrative inquiry. The opportunities we had then, which helped us make sense of our experiences, compose stories to live by, and understand the educational landscape, made us particularly receptive to forming and sustaining a scholarly learning community.

Based on the theoretical and methodological foundations of narrative inquiry, espoused by Clandinin and Connelly (2000), we have continued to embrace narrative inquiry in our ongoing scholarship (Ciuffetelli Parker, 2010; Griffin, 2009; Griffin = Beatty 2010; Kitchen, 2009). Currently, we have come together in a different research context, a new research circle, at a common university. After 4 years of experience with this scholarly learning community, we wonder how these narrative experiences helped us conceptualize the importance of living in community. Three central questions provide a framework for reflecting on our previous research circle experiences and how those experiences become shaped and reshaped through participating in a new research circle as a scholarly learning community of teacher educators. The central questions guiding our inquiry are:

1. What is it like to be part of a new circle, with new colleagues, in a new place?

2. How do our former experiences influence the ability to listen attentively in a new circle?

3. How do our prior experiences contribute to our understanding of self-study and narrative?

We begin by sharing background information about ourselves, situating our work within the discourses of social constructionism and narrative inquiry to assist in providing theoretical and methodological underpinnings that gird our writing experiences. We explain contextual elements that define the previous research circle experiences that each of us brings forth into the current circle. In order to inquire into how our previous research circle experiences have become nested (Clandinin et al., 2006) within the new circle, we reflect upon our three central questions that allow us to better conceptualize the contributions that these experiences have in our evolving understanding of ourselves as teacher educators. As a means to inform other scholars, we conclude by considering the unique nuances and challenges that are present by working together in a scholarly writing research circle.

Our current group includes five faculty members. We (Shelley Griffin, Darlene Ciuffetelli Parker, and Julian Kitchen) are three of the five. Shelley is completing her 4th year of appointment at Brock University. She is a former classroom teacher in Prince Edward Island, bringing experiences of teaching postsecondary elementary music education methods at the 
University of Prince Edward Island and University of Alberta. Darlene is entering her 6th year of teaching elementary instructional methods. Formerly, she had been a classroom teacher, school board literacy consultant, and school administrator. Julian is entering his 5th year teaching education law. Previously, Julian was a classroom teacher who was seconded to the teacher education program at University of Toronto for 7 years.

Darlene and Julian participated in shared narrative research circle experiences during their doctoral studies. When graduate students enrolled in their MEd and PhD work from 19942004, their experiences were facilitated by Dr. Michael Connelly at the Ontario Institute for Studies in Education (OISE), University of Toronto. Likewise, Shelley participated in a narrative research circle (2004-2006) during her doctoral studies, facilitated by Dr. Jean Clandinin at the University of Alberta.

Through their collaborative scholarship, Jean Clandinin and Michael Connelly have created a substantial, well-respected body of literature on teacher education, as well as narrative inquiry, viewed as a research methodology for inquiring into experience. When we met as new faculty members in the self-study group at Brock University, we were drawn together in knowing that we each held prior, meaningful narrative research experiences in these previous contexts, with both Michael Connelly and Jean Clandinin, which brought us closer in our understanding of how we envisioned our scholarly work together.

\section{Situating Experience Within Discourses}

\section{Social Constructionism}

We realize that our aforementioned narrative research circle experiences have been influenced by the discourse on social constructionism whereby knowledge is constructed socially, in relationship with others (Dahlberg, Moss, \& Pence, 1999; Davis, 2004; Davis, Sumara, \& Luce-Kapler, 2008; Hruby, 2001; Packer \& Goicoechea, 2000; Schwandt, 2000). Social constructionism is a social process and does not exist apart from an individual's involvement in the world. Knowing is not passive because the mind is active in the construction of knowledge. Social constructionism acknowledges the importance of language, culture, and history as a part of the learning process.

These thoughts are intimately connected to the framing of narrative research where there is emphasis on the social dimension of inquiry. Clandinin and Murphy (2009) clearly stated that the social aspect is key when situating narrative inquiry research within a Deweyan ontology of experience. These aspects place emphasis in three particular areas: "social dimension of inquiry, temporality of knowledge generation, and continuity that is not merely perceptual but ontological" (p. 599). These authors speak of the necessity of "co-constructed relational ontological commitments” (p. 600). Thus, the socially constructed nature of knowledge is a central component of conceptualizing the relational study of experience.

Such theoretical notions align with our narrative research circle experiences that have been formed relationally, situated within conversation, and help to shape the knowledge that is co-constructed by those in the circle. Supporting this, Davis et al. (2008) articulated that constructionist theories are more focused upon "interpersonal dynamics and collective activity than with personal construals” (p. 102). Within this frame, cognition becomes collective, formed through joint interest where there is a focus upon "conversation patterns, relational dynamics, social habits, and other collective phenomena” (p. 103). As researchers, we have been able to 
overlay our circle experiences with the theory of social constructionism as a means of understanding our relational learning in our narrative research circles.

\section{Narrative Inquiry}

As we socially construct knowledge in the context of our circle engagements, we place an integral focus on the study of experience, inquiring into the storying and restorying of lives through the power of narrative inquiry (Clandinin \& Connelly, 2000). By working with Michael and Jean personally, we were able to understand how their scholarship has been shaped by the work of John Dewey (1938) and thus, we have a deepened understanding of narrative inquiry as a means to both understand and represent the living and telling of lived experiences.

Importantly, through the lens of narrative inquiry, experience is seen as a storied phenomenon and thus, narrative, as a research methodology, is a means for inquiring into storied experiences (Clandinin \& Murphy, 2009). "Lives are lived, told, retold, and relived in storied ways on storied landscapes” (p. 598). Understanding the intricacies of lives and inquiring into experiences in such a manner involves complex dimensions "for narrative inquiry is a kind of inquiry that requires particular kinds of wakefulness” (Clandinin, Pushor, \& Murray Orr, 2007, p. 21).

Thus, it becomes important for us to inquire into our own experiences as we have gently carried these personal and professional stories of participating in narrative research circles with us. We believe, as Clandinin and Connelly (2000) explained, that "Experience is what we study, and we study it narratively because narrative thinking is a key form of experience and a key way of writing and thinking about it" (p. 18). In her writing, Clandinin (2009) elaborated that a Deweyan view of experience embraces learning to be "attentive to temporal unfoldings, as well as to the personal, that is, to the interaction of the personal and social, embodied in each person" (p. 204), while the inquirer remains aware of his/her own relationship to and embodiment within these temporal unfoldings.

Clandinin and Rosiek (2007) reasoned that narrative inquiry begins with an ontology of experience and reality is seen as "relational, temporal, and continuous" (p. 44). We recognize that our understandings of our writing experiences in research circles have happened over time, having a past, present, and future as we continue to story and restory them. We believe that these stories encompass "an exploration of the social, cultural, and institutional narratives within which individuals' [our] experiences were constituted, shaped, expressed, and enacted” (p. 42). We continue to study experience as it is lived, which Clandinin and Rosiek have articulated as "the most defining feature of narrative inquiry" (p. 69). This relational form of inquiry allows us to contextualize our understandings of inquiring into our respective and collaborative research circle experiences.

Although we would not consider our own reflections in this paper of our experiences in research circles to be defined as narrative inquiry, we do strongly attest to the fact that our research orientations are strongly grounded in the work of narrative inquiry and experience, and accordingly, influence and shape our conversations, writing, and desire to work in relation with one another. The lens of narrative inquiry is strongly engrained within each of us as an integral way of understanding both others and ourselves through a methodological frame. Undoubtedly, it becomes not only apparent, but also essential, that we situate our conceptualizations of the unfolding of our past and current research circle experiences within the discourse of narrative inquiry. 


\section{Sitting in Circles}

Through our continued conversations together, we have reflected on the importance of how Jean Clandinin and Michael Connelly, through their narrative frameworks, created a sense of community within an academic context by organizing the narrative research circles at their respective institutions. In order to contextualize this further, we now turn to offer explanations about the structure of the narrative research circles in each institution.

\section{The Narrative Research Circle at University of Alberta: Shelley's Experience}

From Shelley's experience, the research circle takes the form of an hour and a half time to gather on Tuesdays from 12:30 p.m. until 2:00 p.m. The research circle meets weekly on the sixth floor of Education South, in the Centre for Research for Teacher Education and Development (CRTED). Commencing with some warm tea and occasionally a snack, smiles and warm embraces are exchanged as familiar faces gather around a group of large tables that have been placed together to create a circular formation.

It is not uncommon to see graduate students, along with scholars (including international visiting scholars) at all levels, from varied disciplines, come together in a place to listen, share, and learn from one another about the many facets of the research process. Within the spirit of honouring the work of narrative inquiry, stories are offered, reflected upon, carried gently, and given away. It is through this conversation that the research circle becomes a deep place to respect and honour others. It is not necessary to share, one may merely listen, but the circle is open if participants wish to speak.

The conversation generally commences with one person, who, for that academic year, is in the role of facilitating the research circle. This role of facilitation is part of the leadership responsibility for the individual who holds the Myer Horowitz Teacher Education Research Scholar Postdoctoral Fellow within the CRTED. After the conversation is opened, the exchange of talk begins to move around the circle. Often there is a tangible item, such as a stone or talking stick that is passed on from person to person, in the spirit of honouring the speaker. It is not necessary, however, that the conversation only follows the direction in a circular fashion. As people begin to speak, the conversation becomes organic in nature, flowing from community created with those present. Perhaps part of the beauty in this experience is that it is often informal conversation, within a structure that has become formalized by the circular formation.

As a means to continue conversation, it is common that participants bring with them pieces of writing that they wish to share for feedback, including works in progress, rough drafts, doctoral proposals, polished pieces, dissertation chapters, and job talk presentations. Other times, the sharing is a mere opportunity to give voice to both personal and professional thoughts. Often, there are contributions made to the circle through poetry, art, or music. The beauty of the circle is that it is different each week, according to the members present. Importantly, laughter is exchanged and tears are often caught by the community present.

The research circle provides a space for graduate students and scholars to grapple with both ontological and epistemological assumptions that surround and define their own scholarly endeavours. This context offers a safe place to question, inquire, and draw upon previous experiences that formulate current understandings of scholarship and teaching. It is through these re/conceptualizations that many scholars, including myself, have drawn upon the strength of the 
experiences gained through the narrative research circle. These experiences are often carried into other research contexts, such as the one I am presently engaged in at Brock University.

\section{The Narrative Research Circle at University of Toronto: Darlene and Julian's Experiences}

From our experiences, research circles took various forms that all originated from Michael Connelly's courses on narrative inquiry. One example is the Works-in-Progress group, which meets weekly on Tuesdays. It began with a communal dinner prepared by various members of the group, prior to the research circle commencing at 5:30 p.m. The gatherings took place on the tenth floor of the Centre for Teaching and Learning and, as food was shared and people gathered, the couches and chairs were arranged in a circle so that members could share their stories in an intimate setting of safety and comfort. While attendance varied from week to week, there were often more than 20 people.

Michael Connelly was a constant presence. Although the seminar was led by his graduate assistants (us one year), Mick demonstrated commitment and his insightful contributions were critical to the research circle's success. As Shelley mentioned, members volunteered their worksin-progress on various topics, along with discussions on the use of narrative inquiry as an authentic qualitative method. Sometimes, the circle opened with live musical entertainment, a poetry reading, or an arts-based presentation. Fresh cut flowers, brought by one group member, added to the sense of occasion.

Members were encouraged to provide sincere oral feedback as well as reflective writing feedback after the members presented on their specific topic. This act of giving, encouraged by Mick, was crucial to developing intimate personal connections between presenters and members of the circle.

Outside the large research circle, members often formed smaller, more intimate circles. Sharing circles and the friendships we developed with individual members of these circles have been critical to our teaching, research, and our identity as professors of education. We recalled the importance of this work in our doctoral dissertations (Ciuffetelli Parker, 2004; Kitchen, 2005a). It is through these teacher conversations that we were able to grow in relationship. We shared experiences that were integral to our growth based upon our work in larger groups such as The Circle of Five. Darlene reflected:

We have pieced new meanings together in all our narratives. Michael may call this “collaborative autobiographies" or "collaborative narratives". I call it making sense of our own lives, by making sense of others' lives! (Circle of Five writing reflection, April 4, 1994)

Letter writing, which is "similar to journal writing except that you are engaged in a written dialogue with another practitioner," (Connelly \& Clandinin, 1988, p. 48) is also a powerful personal experience method. Michael Connelly, by encouraging his students to write letters in response to student presentations in class and in Works-in-Progress, heightened our appreciation for the perspectives of others in our personal professional development. Ten years after we had begun to write letters to one another in 1993, our correspondence had grown to over 75 letters, 180 pages, and 72,000 written words (Kitchen \& Ciuffetelli Parker, 2003). More importantly, our letters and conversations became a mainstay of our personal and professional growth. In addition, these experiences inform our reflections on the three questions posed within 
our current self-study group at Brock University, as we attempted to better understand how our narrative research circle experiences overlap.

\section{Inquiring Into Shared Questions}

It is because of these experiences that we now unpack and restory our previous narrative circle experiences, making sense of how they have become shaped and reshaped through participating in a new scholarly community of teacher educators. In order to provide context for the following conversation, we have created an opportunity for the reader to sit with us and listen in the setting of a circle. Here, we frame our reflections on the three questions alongside our three-way conversation.

Each enjoying a warm cup of tea, we are seated on the black leather sofas in Shelley's living room. The smell and dim light of candles add a calming, quieting presence to our dialogue. Together, we converse about the central questions posed within our group to understand better how our research circle experiences overlap.

As we begin talking, Darlene asks Shelley, "What is it like to be part of a new circle, with new colleagues, in a new place?” Shelley ponders a moment and begins to share:

Leaving my research circle community behind in Alberta, in January, 2007, I recall welcoming the opportunity to sit with colleagues, in a comfortable space to share and talk about matters of teaching, scholarship, and service. The self-study group became very important to me as a means to sustain some of my collaborative interests in scholarship. I immediately took interest in Julian's and your [Darlene's] experiences of scholarly work in narrative. There was an unspoken understanding of how we saw ourselves living as scholars based upon our experiences of conceptualizing the importance of narrative work in teacher education. We seemed to share similar ontological and epistemological stances around the place that our individual experiences held in leading us toward our current positioning as scholars. Our conversations became formulated and shaped around our own personal and professional narratives that led us to Brock University. These conversations have, and continue to sustain us within this new circle. (S. Griffin, personal communication, May 2, 2008)

Shelley is curious about Darlene's thoughts as well. She continues by asking her, "What is it like for you, being part of a new circle?” Darlene smiles as she begins to explain:

When I first began my appointment at Brock University, Julian had not yet been hired. There seemed to be no other colleague who seemed to know the narrative inquiry background from which I came. Instead and, rather, I was dubbed the expert narrative researcher early on. I embraced a need to collaborate with others in similar teaching positions as mine and so, when there arose an opportunity to write about my experiences as a co-ordinator of an elementary methods course, I quickly asked my secondary counterpart, Lorenzo Cherubini. He willingly accepted to partake in a self-study of our practice as new hires to a leadership role in co-ordinating methods. As a result, we have presented our work at two conferences and have re-submitted a manuscript from this work (Ciuffetelli Parker \& Cherubini, 2008). The first connection to Lorenzo Cherubini in my work as a new tenure-track professor led to my second year where, when Julian joined our faculty, we formed a self-study group of nine new hires. We quickly have become a close-knit community in which we have realized that the sharing of food in 
more intimate spaces (such as members' homes), and sharing of personal and professional stories has advanced our professional work even further. (D. Ciuffetelli Parker, personal communication, May 2, 2008)

As Darlene completes her thought, she invites Julian into the conversation by asking his insights on how he feels about being part of a new research circle. With ease, he replies:

Coming to a new circle was easy for me. The presence of you, Darlene, smoothed the transition. More importantly, I feel a strong need to work in collaboration with others and to feel a sense of community. As a new professor, though, I had been a teacher educator at OISE/UT for 7 years, I welcomed the opportunity to speak honestly with peers who shared similar experiences as new faculty. I also welcomed finding a safe haven in which to critically examine the existing institutional practices and culture. (J. Kitchen, personal communication, May 2, 2008)

In a moment of silence, we begin to realize that our stories are resonating with one another. As we continue to converse, we begin to think about attentive listening within research contexts. Julian asks Shelley, "How do your former experiences influence the ability to listen attentively in a new circle?” After thinking for a few moments, Shelley offers:

I came to understand more deeply the importance of listening as a means to understand another, and as a result, ask questions of myself regarding the study of my own beliefs about teaching and learning. Through listening to others, I began to hear myself within other's stories, and accordingly, better understand my own thought processes around scholarship, questioning why I believed and conceptualized my thoughts in the ways that I did. My attentiveness to listen to others and ask questions allows me to not only understand the other, but also to understand myself. (S. Griffin, personal communication, May 2, 2008)

Shelley asks, "What about you, Julian? How does listening inform your participation in a research circle?” Julian articulately responds:

My previous experiences prepared me well for the new circle. As a member of groups and communities, I learned many lessons about effective listening, thoughtful feedback, developing trust within a group, and dealing with difficult issues in a sensitive manner. Experiences in group facilitation helped me to play an important role in the development of the group processes used in the first year and the revisions in the subsequent years. (J. Kitchen, personal communication, May 2, 2008)

Julian continues by saying, "Would you agree, Darlene? How do you think we came to know about the importance of being attentive listeners?” Sipping on her tea, Darlene thoughtfully shares:

Every time I listen to another's story, I hear my own in it. It is through this authentic connection to others, by listening attentively, which has proven successful in our new circle. I knew that such principles as trust and a safe community in which to interact were paramount to my role as a teacher educator and researcher and to my own professional development. My circle experiences have taught me what it means to be authentic when I am in circle with others. Common core values, while honouring diversity of perspectives, has been important to how I have come to listen attentively to others and to help engage others in our new group. (D. Ciuffetelli Parker, personal communication, May 2, 2008) 
Through listening to one another, we begin to hear the value in attentive listening within research contexts. Through this process, we honour one another's experiences and collaboratively recognize that Michael and Jean, in their scholarship, live their lives as attentive listeners. By example, they have shown each of us that attentive listening is truly essential to the relational research of narrative inquiry.

As teacher educators, we now find ourselves in the context of a self-study group at Brock University. In this group, we have formed a research circle which honours both independent and collaborative inquiries to enhance all aspects of academia: our teaching, scholarship, and service. As we lay our previous circle experiences alongside our current context, Shelley asks Julian, "How do your prior experiences contribute to your understanding of self-study and narrative?" Being familiar with self-study, Julian elaborates:

My understanding of self-study is informed by my work in narrative inquiry. This has taught me the importance of attending to one's own stories and the stories of others. Through narrative communities of practice at OISE/UT, I also learned how to reflect on practice within a circle of colleagues. Through my work in self-study, I recognized the importance of collaboration in making sense of our experiences and practices as teacher educators. Upon arriving at Brock University, I knew that I wanted to help form a selfstudy group. Darlene and Tiffany Gallagher, another colleague in our department, independently proposed the same idea. (J. Kitchen, personal communication, May 2, 2008)

Julian turns to Darlene and asks, "How have your prior experiences impacted self-study and narrative?”

Like you, Julian, my understanding of self-study is rooted by my work in narrative inquiry. The power of story and understanding, at a deeper level, our own and other's stories, brings with it insights into our work with our students and colleagues. The research circles at OISE/UT were my ground work for my future work in teacher education and in my relationships with my new colleagues. (Ciuffetelli Parker \& Volante, 2009; D. Ciuffetelli Parker, personal communication, May 2, 2008)

Darlene wonders, “Is this similar for you, Shelley?” Shelley suggests:

Well, based upon my journey as a doctoral student, I began to formulate increased understanding about narrative inquiry as a method of inquiry to represent both the living and telling of stories of experience. I came to find great value in this thoughtful form of scholarship as I was able to gain a voice in my own research, and look at my experiences as a process through which I could better understand my beliefs about teaching and learning. Subsequently, this allowed me to inquire into the music experiences of children, both in- and out-of-school (Griffin, 2007, 2009, 2010). Through developing my doctoral research interest in this area, my continued attempt to understand self certainly resonated when I was then invited to participate in the self-study group. The underlying pedagogy of community and safety that was created by Jean Clandinin in the previous research circle continues to stay with me as I hold these beliefs near to me at Brock University. In this light, there is a subconscious way of desiring to be present to others, relationally, in a meaningful way in the circle. These experiences become nested within my current experiences. It is through my reflection and re/conceptualization of self that I begin to 
better articulate my thoughts around my growth process as an academic. (S. Griffin, personal communication, May 2, 2008)

\section{Carrying Circle Experiences to Brock University}

Through the three questions outlined in our conversation, we have reflected on our prior experiences in research circles in order to understand how they have informed our present participation as we work together in community at Brock University, and to consider how the lessons learned from these experiences can inform our future work in research circles as we work alongside one another. In addition, we necessarily reflect upon the unspoken tensions that lie within our collaborative encounters in the research circle. Acknowledging these tensions keeps us authentic and accountable in our work together.

Trust, we learned from prior experiences, is essential to developing a safe and caring community of scholars. As a group, we recognized the need for making our circle space personal rather than impersonal. After our first year, we met in less formal settings, such as each other's homes, reinforcing the importance of feeling relaxed in a place in which we can engage authentically and live respectfully in a circle.

The safety of the sharing circle has helped us to incubate ideas which we can then share with others. In the parlance of James Heap, former Dean of Brock University's Faculty of Education, it is important that our work has an impact on scholarship and practice. Heap (2007) argues that the tension between the tower and the field can be resolved by focusing less on traditional scholarly objectives and more on scholarly impact objectives that recognize the importance of provoking discussion in the field; practitioner utilization of theories, practices, and materials; and the improvement of education. As faculty members, we have been pondering how our own teaching, scholarship, and service may have impact. In reflecting on impact, Julian shared his insights:

By being in a self-study community, I felt that my research of teacher education practices was valued within the institution. This has contributed to my commitment to continuing this type of work (Kitchen, 2005b, 2005c, 2008), even as I explore other types of scholarly research. Also, the study of our self-study community has also led to interesting collaborative scholarship (Kitchen \& Stevens, 2008), including an article (Kitchen, Ciuffetelli Parker, \& Gallagher, 2008) and a book chapter (Kitchen \& Ciuffetelli Parker, 2009). I foresee that the self-study group will continue to play an important role in my ongoing scholarship. (J. Kitchen, personal communication, May 2, 2008)

By attending to Julian's words, it becomes evident that our circle experiences within our selfstudy group have led us toward impacting others within the faculty, as well as within the broader scholarly community. As we live out our circle experiences in a new place, we think it is important that we share our experiences with others who are interested in developing scholarly learning communities. Thus, we consider how our experiences might influence others in academic contexts who wish to engage in similar research circle experiences. How might a circle model take hold elsewhere?

\section{Musings in the Midst}

As we consider the value of our research circle, we also realize that there are tensions that exist and questions that go unspoken within our circle. At this point, some of these questions have been unanswered. Perhaps they may even continue to go unanswered. Inquiring into our 
continued individual and collaborative research circle experiences allows us to make these tensions and questions more explicit and transparent. There are many nuances that underpin the uniqueness within our research circle. We point out these wonderings for further consideration.

We have identified that in the spirit of collaboration; we honour attentive listening. Each of us values the importance of listening to one another as we work through our individual and collaborative experiences and scholarly pursuits. Yet, how do we each know that we are truly attentive listeners? It appears to be an unspoken understanding, in fact, a necessary point of inclusion. Is this skill merely modelled by one another? How does listening manifest itself within a research circle? We wonder.

We have spoken about a vast array of advantages that we have experienced by being involved in the research circle, but we, too, wonder if there are consequences to being involved in a research circle. How is it perceived? Is the circle in fact tight so that others may not break in? Each year, we have made an open attempt to involve others in the circle who may be interested in becoming part of this scholarly group. Do others see the circle as insular? Although we feel that we have been inclusive, others may perceive that they have been excluded. Do they perceive an unspoken code of inclusion? As members, how do we become accountable to this? We wonder.

It is important to consider the boundaries that lie between our circle and our friendships. We do not know or feel this boundary to be clear. Where does the circle stop and the friendship begin? Is the friendship embedded within our scholarly pursuits and continued conversation? Perhaps the two are nested within one another such that it is not advantageous for the boundary to be defined. How would we know that we are not merely friends writing together? We wonder.

Connected to this idea is the importance of keeping one another authentic. We engage in both individual and collaborative writing. Despite our friendships, we realize that in order to sustain our writing, while offering support, we do need to be articulate critics. Together, we have provided opportunities for this to unfold. For example, after our monthly self-study meetings, group members often offer a critical written reflection to the person who has shared his/her work that day. This dialogue is critical to the work of self-study as Samaras and Freese (2009) explained: "Self-study is not done in isolation, but rather requires collaboration for building new understandings through dialogue and validation of findings" (p. 5). As collaborators, this feedback helps to advance our work. Engaging in this critical discourse becomes a means to move our scholarship forward. Beyond our friendship, we do provide necessary encouragement for one another, while ensuring that we are also articulate critics for each other's scholarly pursuits.

Our scholarship in research circles has connected us across institutions, disciplines, and experiences. We continue to find value in our work together as we socially co-construct meaning through our narrative understandings, and find sustenance in our engagement as a community of teacher educators. As we continue to explore how these experiences mould us as scholars, we wonder about how our philosophical underpinnings regarding the philosophy of a research circle might become embedded into our teaching experiences. Do these experiences as scholars play out and influence our vision for working with teacher candidates? How does the philosophy of a research circle influence our other independent or collaborative scholarly endeavours? We wonder. 
All of these musings help us to be accountable and honest with one another. Although we do not have definitive answers regarding these wonderings, we acknowledge the importance of identifying and discussing the secret nuances that may be unique to our research circle.

\section{Continuing In Circle}

Our circle influences lead us toward improving our practice. As new scholars, we value the fact that the research circle has been an impetus for writing. It has provided a space for sharing, questioning, and critiquing. We recognize that the engagement in our circle helps to inform us as we read, engage in, and advance our scholarly activities. Through our prior circle experiences, along with our current experiences, we continue to learn to be researchers. Therefore, the circle is a haven where we mutually grow, composing our identities on our scholarly journeys.

Through coming to a new circle, we carried our personal and professional stories into a different context while recognizing that these stories influenced and helped us to improve our practice. We honour the fact that we continue to carry these stories to our circle together and we support each other as these narratives unfold and become reshaped and restoried by the influences of one another.

As former graduate students, we are grateful to have had the opportunity to work alongside Michael Connelly and Jean Clandinin. We are cognizant of the tremendous influence that these scholars have had on our graduate journeys and on our continued practice as teacher educators. Among many, we are three teacher educators who are indebted to their impact within the field of narrative inquiry. It is because of them that we were compelled to write this article and inquire further into how we live in community within our research circle experiences. To them, we owe our deepest gratitude.

As we think about the living, telling, storying, and restorying of our continued circle experiences, we realize that it has been integral to be mindful of "attending to the particularities of place or places where events were lived and told as well as to the place or places where stories of those experiences were told and retold” (Clandinin, 2009, p. 204). By telling and reshaping these stories, we will continue to reflect upon and reshape our answers to the three underlying questions we pondered. Through narrative inquiry and self-study, inquiring into such questions contributes to our professional growth and to the improvement of practice and scholarship. As we move forward as members of an evolving circle, we continue to live out our previous, familiar in circle experiences, welcoming the opportunity to grow, by sharing with one another and developing common re/conceptualizations through the process. 


\section{References}

Clandinin, D. J. (2009). Troubling certainty. Narrative possibilities for musiceducation. In M. S. Barrett \& S. L. Stauffer (Eds.), Narrative inquiry in music education: Troubling certainty (pp. 201-209). Dordrecht, The Netherlands: Springer.

Clandinin, D. J., \& Connelly, F. M. (2000). Narrative inquiry: Experience and story in qualitative research. San Francisco, CA: Jossey-Bass.

Clandinin, D. J., Huber, J., Huber, M., Murphy, S. M., Murray Orr, A., Pearce, M., \& Steeves, P. (2006). Composing diverse identities: Narrative inquiries into the interwoven lives of children and teachers. New York, NY: Routledge.

Clandinin, D. J., \& Murphy, M. S. (2009). Relational ontological commitments in narrative research. Educational Researcher, 38(8), 598-602.

Clandinin, D. J., Pushor, D., \& Murray Orr, A. (2007). Navigating sites for narrative inquiry. Journal of Teacher Education, 58(1), 21-35.

Clandinin, D. J., \& Rosiek, J. (2007). Mapping a landscape of narrative inquiry: Borderland spaces and tensions. In D. J. Clandinin (Ed.), Handbook of narrative inquiry: Mapping a methodology (pp. 35-75). Thousand Oaks, CA: Sage.

Ciuffetelli Parker, D. (2004). Literacy narratives: Writing and relating letters and stories of teacher knowledge, identity and development. Unpublished doctoral dissertation, Ontario Institute for Studies in Education, University of Toronto, Toronto, ON, Canada.

Ciuffetelli Parker, D. (2010). Writing and becoming [a teacher]. Teacher candidates' literacy narratives over four years. Teaching and Teacher Education, 28, 1249-1260.

Ciuffetelli Parker, D. \& Cherubini, L. (2008). Living in the margins of teaching and scholarship: Two professors' program and leadership in a learning faculty. Excelsior, 3(1), 15-26.

Ciuffetelli Parker, D., \& Volante, L. (2009). Responding to challenges posed by summative teacher candidate evaluation within a formative assessment framework: A collaborative selfstudy of practicum supervision by faculty. Studying Teacher Education, 5(1), 33-44.

Connelly, F. M., \& Clandinin, D. J. (1988). Teachers as curriculum planners: Narratives of experience. Toronto, ON: OISE Press.

Dahlberg, G., Moss, P., \& Pence, A. (1999). Beyond quality in early childhood education and care: Postmodern perspectives. London, England: Falmer Press.

Davis, B. (2004). Inventions of teaching: A genealogy. Mahwah, NJ: Lawrence Erlbaum.

Davis, B., Sumara, D., \& Luce-Kapler, R. (2008). Engaging minds: Changing teaching in complex times (2nd ed.). New York, NY: Routledge.

Dewey, J. (1938). Experience and education. New York, NY: Macmillan.

Griffin, S. M. (2007). The musical lives of children: A missing perspective in elementary school music. Unpublished doctoral dissertation, University of Alberta, Edmonton, Alberta, Canada. 
Griffin, S. M. (2009). Listening to children's music perspectives: In and out of school thoughts. Research Studies in Music Education, 31(2), 161-177.

Griffin, S. M. (2010). Inquiring into children's music experiences: Groundings in literature. Update: Applications of Research in Music Education, 28(2), 42-49.

Griffin, S. M. = Beatty, R. J. (Equal authorship). (2010). Storying the terroir of collaborative writing: Like wine and food, a unique pairing of mentoring minds. Mentoring \& Tutoring: Partnership in Learning, 18(2), 177-197.

Heap, J. (2007). Betwixt tower and field: Autonomy, accountability and accreditation in Faculties of Education. Keynote speech at the Ontario Ministry of Education/Faculties of Education Forum, Toronto, May 2007.

Hruby, G. G. (2001). Sociological, postmodern, and new realism perspectives in social constructionism: Implications for literacy research. Reading Research Quarterly, 36(1), 4862.

Kitchen, J. (2005a). Relational teacher development: A quest for meaning in the garden of teacher experience. Unpublished doctoral dissertation, Ontario Institute for Studies in Education, University of Toronto, Toronto, ON, Canada.

Kitchen, J. (2005b). Conveying respect and empathy: Becoming a relational teacher educator. Studying Teacher Education, 1(2), 194-207.

Kitchen, J. (2005c). Looking backwards, moving forward: Understanding my narrative as a teacher educator. Studying Teacher Education, 1(1), 17-30.

Kitchen, J. (2008). Using written feedback to promote critical reflection: A teacher educator responds to reflective writing by preservice teachers. Excelsior, 2(2), 37-46.

Kitchen, J. (2009). Passages: Improving teacher education through narrative self-study. In D. Tidwell, M. Heston, \& L. Fitzgerald (Eds.), Methods for self-study of practice (pp. 35-51). Dordrecht: The Netherlands: Springer.

Kitchen, J., \& Ciuffetelli Parker, D. (2003). Corresponding conversations: Combining letters and conversations to create a more powerful tool for collaborative self-study. American Educational Research Association, Chicago, April, 2003.

Kitchen, J., \& Ciuffetelli Parker, D. (2009). Developing self-study communities of practice. In C. Lassonde, S. Galman, \& C. Kosnik (Eds.), Self-study research methodologies for teacher educators (pp. 101-122). Rotterdam, The Netherlands: Sense.

Kitchen, J., Ciuffetelli Parker, D., \& Gallagher, T. (2008). Authentic conversation as faculty development: Establishing a self-study group in an education college. Studying Teacher Education, 4(2), 157-171.

Kitchen, J., \& Stevens, D. (2008). Action research in teacher education: Two teacher educators practice action research as they introduce action research to preservice teachers. Action Research, 6(1), 7-28.

Packer, M. J., \& Goicoechea, J. (2000). Sociocultural and constructivist theories of learning: Ontology, not just epistemology. Educational Psychologist, 35(4), 227-241. 
Samaras, A. P., \&, Freese, A. R. (2009). Looking back and looking forward: An historical overview of the self-study school. In C. A. Lassonde, S. Galman, \& C. Kosnik (Eds.), Selfstudy research methodologies for teacher educators (pp. 3-19). Rotterdam, The Netherlands: Sense.

Schwandt, T. A. (2000). Three epistemological stances for qualitative inquiry: Interpretivism, hermeneutics, and social constructionism. In N. K. Denzin \& Y. S. Lincoln (Eds.), Handbook of qualitative research (2nd ed.) pp. 189-213. Thousand Oaks, CA: Sage. 